\title{
Proposta de metodologia de prevenção de resíduos e otimização de produção aplicada à indústria de confecção de pequeno e médio porte
}

\author{
Proposal of methodology for waste prevention and optimization of production applied to the \\ clothing industry of small and medium businesses
}

\author{
GUIMARÃES, Bárbara Andressa \\ Especialista; Universidade Positivo \\ barby.and@bol.com.br \\ MARTINS, Suzana Barreto \\ Doutora, Universidade Estadual de Londrina \\ suzanabarreto@onda.com.br
}

\begin{abstract}
Resumo
O setor brasileiro de vestuário, mais especificamente as indústrias de pequeno e médio porte do setor de confecção são responsáveis por elevada capacidade de produção, alto índice de empregabilidade e geração de renda, contribuindo como fonte de desenvolvimento do país. Por outro lado, a elevada produção desse setor gera impactos ambientais significativos. Neste cenário, este trabalho busca analisar o processo produtivo de confecções de pequeno e médio porte e a geração de resíduos destes, partindo da análise de propostas existentes de prevenção de geração de resíduos, e apresentar proposta de metodologia para implementação de produção mais limpa neste Setor.
\end{abstract}

Palavras- chave: Indústria de confecção; Sustentabilidade; Produção mais limpa.

\begin{abstract}
The brazilian clothing sector, especially the industries of small and medium size clothing sector are responsible for high production capacity, high employability and income generation, contributing as a source country's development. On the other hand, the high production of this sector generates significant environmental impacts. In this context, this paper aims to analyze the process of garment manufacturing in small and medium businesses and their resulting waste, based on an analysis of existing proposals for the prevention of waste generation, and presenting the methodology for implementation of cleaner production in this sector.
\end{abstract}

Keywords: Clothing industry; Sustainability; Cleaner production.

\section{Introdução}

O ser - humano sempre teve toda estrutura natural e ambiental, e nunca foi privado de usufruir o que o meio-ambiente tem para oferecer, mas o mau uso destes recursos, a ambição humana e o consumismo desenfreado acabaram mudando este cenário. Mesmo sendo parte da natureza, o homem age muitas vezes sem consciência e não pensa no futuro e nos limites do ecossistema, o que já o fez ultrapassar os limites de quase tudo o que podia 
utilizar e explora ainda sem limites e sem conscientização. Os reflexos destas escolhas e descaso com o Meio Ambiente são muitos e com resultados negativos para todos: um ar menos puro, extinção de inúmeras espécies, muitas doenças antes desconhecidas, diminuição da qualidade de vida, o efeito estufa, diminuição da quantidade de água potável em números elevados e que acarretam gradativamente inúmeros problemas.

O homem e suas atitudes estão ferindo sua própria origem e exterminando seu futuro. O problema existe e a consciência sobre o mesmo está mais claro na mente das pessoas de vanguarda em todo o mundo, que começaram a perceber e se interessar pelo assunto, e a se posicionar, tomando atitudes em pequenos detalhes ou totalmente radicais, para tentar boicotar atividades, produtos e atitudes que possam desfavorecer o meio ambiente. As pessoas começam a ver o jogo de interesses financeiros que o mundo tornouse, com tudo girando em torno do dinheiro e poder, esquecendo-se do Planeta que é o nosso abrigo, da natureza da qual fazemos parte e da saúde de milhões de pessoas.

Muito se obteve em avanços, tecnologia, poder, novidades, descobertas, mas com isto perdeu-se a essência, a qualidade em família, o respeito pelo seres vivos, pela natureza e pelo próprio ser - humano, que ao invés de dominar as máquinas que inventou e o dinheiro que obteve, é por sua vez dominado por eles. Para Lipovetsky (1987, p: 182): 'A sociedade de consumo é programação do cotidiano: ela manipula e quadricula racionalmente a vida individual e social em todos os seus interstícios; tudo se torna artifício e ilusão a serviço do lucro capitalista e das classes dominantes.

Com o foco em lucro sobre lucro detalhes importantes são esquecidos ou desconsiderados. Mas devido à preocupação mundial em meio às mudanças climáticas abruptas, derretimento das calotas polares e outros fenômenos naturais excepcionais, como Tsunami, El Nino e muito outros, a atenção para o resultado da industrialização e sobre a natureza começaram a ganhar evidência devido a magnitude dessas ocorrências. Hoje existem ONGs, projetos, leis, incentivos, empresas e produtos para atender a um público que possui novos valores e preocupação com o meio ambiente. Profissionais de diversas áreas utilizam seus trabalhos como forma de auxiliar a disseminação da importância da preservação ambiental.

De outro lado, as empresas podem contribuir significativamente ao oferecer produtos e serviços com qualidade, respondendo as expectativas, desejos e necessidades dos consumidores. Para tal, é primordial a responsabilidade com a sociedade, seu respeito e contribuição para o desenvolvimento econômico e social de sua região e de seu país, uma vez que as decisões e ações da empresa são fundamentais para o resultado final de credibilidade e valor da empresa. As mudanças positivas começam nas empresas, por seu poder de persuasão, mas também pela exigência do consumidor, que possui atitude, valores e parâmetros que interferem na decisão e poder de compra.

Segundo Popcorn (1997, p.307) uma das tendências para o futuro seria a do consumidor vigilante, o qual é alerta, disposto a proteger seus interesses e que não tolera deslizes por parte da empresa. Esse consumidor busca e reconhece seus direitos. Esta tendência em ascensão levará as empresas a cada dia mais buscar por melhorias e diferenciais para manter seus atuais clientes, bem como atingir potenciais clientes.

A mudança de atitude de grandes empresas frente a esta questão adquire importância, devido a seu poder econômico, de formação e manipulação de opinião, além de oferecer acesso fácil da oportunidade de compra aos clientes de produtos que se preocupam com o meio ambiente. No setor têxtil e de confecção algumas ações possíveis de aplicação são: utilização de materiais orgânicos, reposição de partes de objetos para 
concerto e reutilização do mesmo, diminuição da quantidade de material e embalagem utilizada oferecendo a mesma ou qualidade superior dos produtos, ciclo de vida do produto estendido, produtos com alta eficiência e performance, multi-funcionalidade, oferecer serviço para manutenção e upgrade do produto, ou somente oferecer o serviço, praticando a desmaterialização.

Para Manzini e Vezzoli (2002) as empresas são atores sociais, e possuem conhecimento de organização e de tomada de iniciativa, o que lhes confere papel central para promover ações de mudanças dentro delas visando a sustentabilidade e uma das suas dimensões, como a responsabilidade social. Em contrapartida, existe o receio da perda da competitividade por parte de algumas empresas em relação a essas ações de mudanças, mas por outro lado, a convergência e direcionamento da empresa para ações voltadas a sustentabilidade pode se converter em um fator diferencial perante as outras empresas. Assim, por meio de uma análise e reorganização das empresas em direção a produção mais limpa e ações voltadas para a sustentabilidade, além de destacar-se das demais, essas ainda terão a oportunidade de otimizar seus lucros e desempenho.

A disseminação da sustentabilidade e sua aplicação no cotidiano das pessoas e em empresas é um dos caminhos para buscar o equilíbrio para viver bem, com responsabilidade, atitude e inteligência. A sustentabilidade é um ciclo que se auto-sustenta, sendo que o tripé do mesmo é o setor econômico, o ambiental e o social, e esses três estão interligados. A sustentabilidade deve ser inserida em todas as esferas: nas empresas, nos lares, no dia a dia e nas atitudes individuais.

No Brasil um dos setores industriais que mais crescem, geram crescimento econômico, empregos e que é fonte intensa de investimentos é a indústria do vestuário. Por sua vez, a presença da moda, inerente desse Setor, exerce grande influência, contribuindo significativamente para o seu desenvolvimento.

Em contrapartida, a indústria do vestuário é responsável por significativos impactos ambientais tanto no cenário nacional como mundialmente, decorrente de seus processos produtivos e do elevado índice de consumo de seus produtos que são descartados muito antes do final do seu ciclo de vida útil. Portanto, é fundamental estudar e reformular os seus processos produtivos, suas etapas e seqüências, com vistas a impulsionar uma produção mais limpa com o intuito de melhorar a eficácia da produção e reduzir seus impactos ambientais.

Um dos caminhos para contribuir com essa mudança de cenário e o objetivo desse trabalho é a proposta de uma metodologia de produção mais limpa passível de ser aplicado em indústrias de pequeno e médio porte de confecção, com o intuito de melhorar seus processos produtivos, promover a responsabilidade social e impulsionar ações sustentáveis.

\section{A importância da Indústria Têxtil e de Vestuário no Contexto Brasileiro}

Segundo Santana (2007) o setor de confecções é um dos principais empregadores do País, sendo o segundo maior empregador da indústria de transformação da qual representa $18,6 \%$ do produto interno bruto. O parque nacional têxtil consome anualmente, mais de $1.400 .000 \mathrm{t}$ de diversas matérias-primas.

Segundo a ABIT (2010): o faturamento da cadeia têxtil e de confecção é de US\$ 47,4 bilhões (em 2008, registrou US\$ 46 bilhões. Para o ano de 2010 a expectativa é de que o setor atinja faturamento de US\$ 51 bilhões); investimentos no setor: US\$ 850 milhões em 2009, contra US\$ 1,5 bilhão em 2008; a produção média de confecção: 9,8 bilhões de peças; 
na área possui 1,7 milhões de trabalhadores empregados, dos quais $75 \%$ é mão-de-obra feminina; no Brasil este setor é o segundo maior gerador do primeiro emprego; o nosso país é o quinto maior produtor têxtil do mundo e o segundo maior produtor e terceiro maior consumidor de denim do mundo; O setor têxtil e de moda representa 13,15\% dos empregos na Indústria de transformação e cerca de 3,5\% do PIB total brasileiro.

Dados do SENAI/CETIQT, Centro de Tecnologia da Indústria Química e Têxtil (2008) apontam que: o valor da produção da cadeia Têxtil e de Confecção representa o equivalente a pouco mais de $4 \%$ do PIB total brasileiro e de $17 \%$ da indústria de transformação. Emprega cerca de 1,5 milhões de trabalhadores, o que representa $1,7 \%$ da população economicamente ativa do país, e $16,9 \%$ do total dos trabalhadores alocados na indústria da transformação. Isso faz dela a segunda maior empregadora formal deste grupo.

Os quadros abaixo demonstram, conforme a ABIT (Associação Brasileira da Indústria Têxtil e de Confecção) (2009, p: 8) os investimentos do BNDES (Banco Nacional de Desenvolvimento Econômico e Social) nas indústrias têxtil e de confecção em 2008 e 2009 e a perspectiva de crescimento para o ano corrente de 2010.

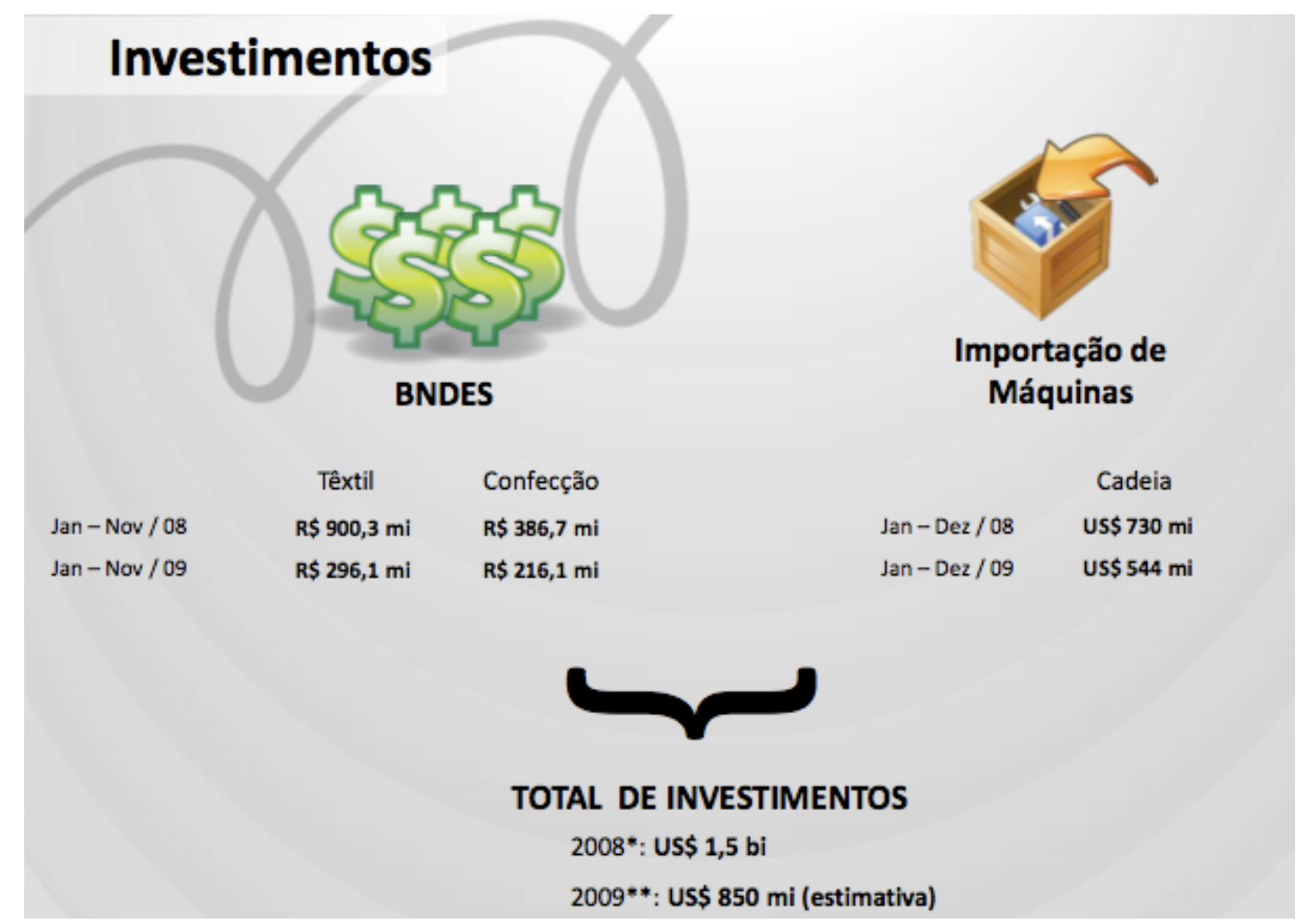

Quadro 1 - Investimentos na indústria têxtil e de confecção

Fonte: ABIT (2009) 


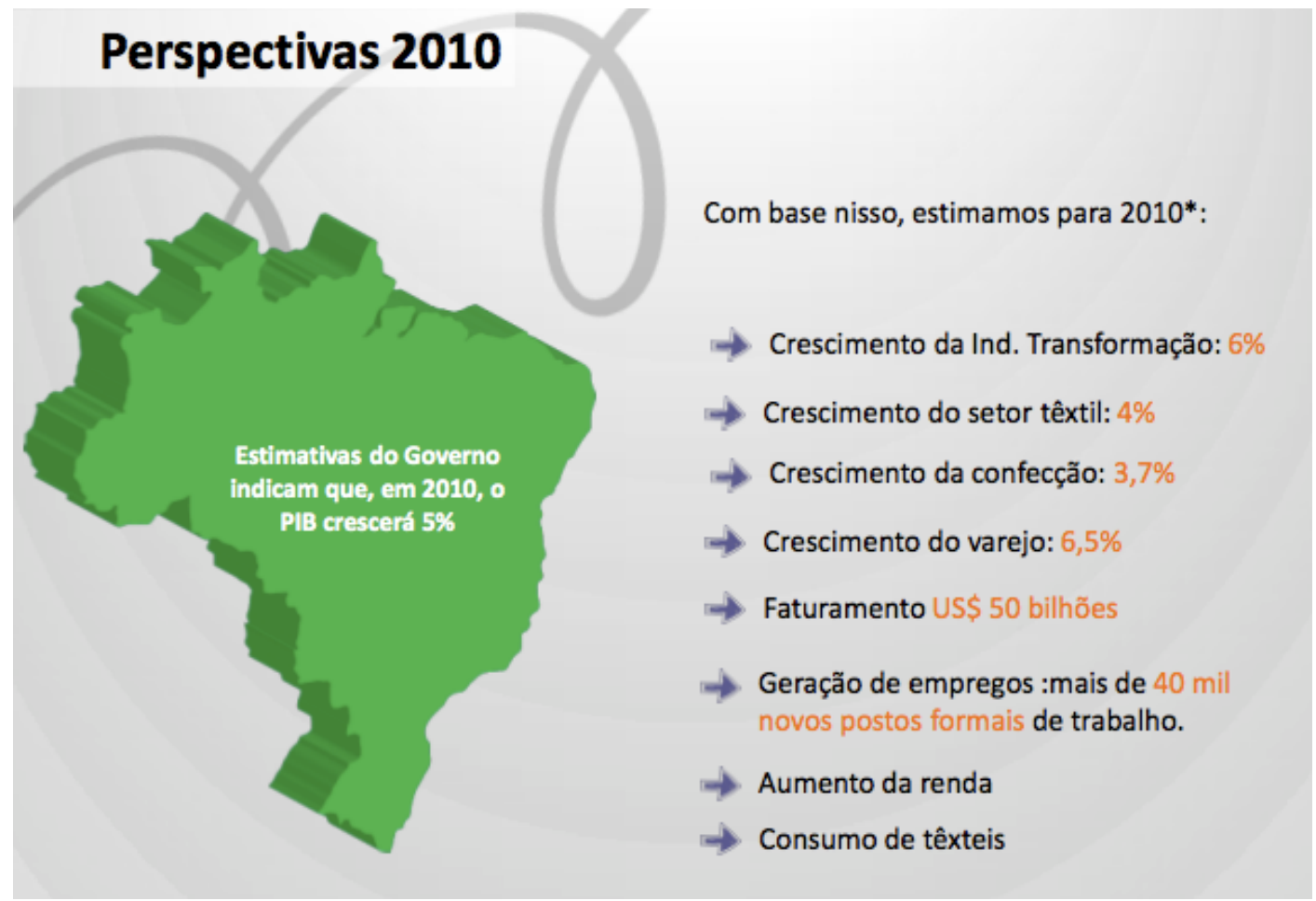

Quadro 2 - Investimentos na indústria têxtil e de confecção Fonte: ABIT (2009)

\section{Cenário do Setor de Confecções de Pequeno d Médio Porte}

Segundo o SEBRAE (2010) cada estado brasileiro possui seus critérios para classificar as empresas segundo seu porte (micro, pequena, média e grande). Um dos critérios é pela quantidade de funcionários. As microempresas possuem até 19 empregados, as de pequeno porte entre 20 a 99 e as de médio porte de 100 a 499 empregados.

As pequenas e médias empresas são responsáveis por grande parte do desenvolvimento e faturamento no cenário brasileiro. Segundo o SEBRAE (2004) 59\% dos 266,4 mil novos empregos gerados com carteira assinada em Março de 2010, foram criados pelas micro e pequenas empresas.

\begin{tabular}{|l|l|}
\hline Porte & Empregados \\
\hline Microempresa & Até 19 empregados \\
\hline Empresa de pequeno porte & 20 a 99 empregados \\
\hline Empresa de médio porte & 100 a 499 empregados \\
\hline Empresa de grande porte & Mais de 499 empregados \\
\hline
\end{tabular}

Quadro 3 - Classificação das empresas no Brasil em portes, pelo número de empregados Fonte: SEBRAE (2004)

\section{Evolução das Questões Ambientais nas Indústrias no Brasil}

Para Manzini e Vezolli (2002) o desenvolvimento de produtos e serviços deve aderir o critério Life Cycle Design (LCD), Ciclo de Vida do Produto, com o propósito de reduzir a carga ambiental associada ao ciclo de vida de um produto, onde o sistema de produto em 
todas as suas fases, os inputs de materiais e energia sejam reduzidos ao máximo, diminuindo seus efeitos prejudiciais. Todo o ciclo de vida do produto: pré-produção, produção, distribuição, uso e descarte, devem ser analisados, mapeando-se os processos, os inputs e outputs e gerando alternativas de otimização e eficiência.

O Brasil possui inúmeras riquezas naturais e é conhecido mundialmente pela criatividade de seu povo. O setor têxtil do país é significativamente importante para sua economia e desenvolvimento, setor esse que passou por inúmeras mudanças no decorrer dos anos nos quesitos de gerenciamentos ambientais, segundo o Centro Nacional de Tecnologias Limpas SENAI (CNTL) (2007) é possível analisar as tendências seguidas por essa evolução nas últimas décadas no Brasil:

Nas décadas de 50 e de 60, classificadas como décadas de DISPOSIÇÃO, referente às atitudes em relação ao resíduo gerado pelas indústrias; houve o começo do desenvolvimento de padrões de qualidade e de emissão, o meio ambiente era quase livre, a diluição dos resíduos e emissões eram feitos na água e no ar, inexistência da responsabilidade das empresas com o seu impacto ambiental produzido;

Nas décadas de 70 e de 80 , classificadas como décadas de TRATAMENTO, houve o sistema de licenciamento e impacto ambiental, com atitude reativa: cumprimento das normas ambientais, controle no final do processo (end-of-pipe) e a responsabilidade das empresas isoladamente.

A partir da década de 90, inicia-se a época classificada como de PREVENÇÃO e que é aplicada nos dias atuais, onde foram criados instrumentos econômicos e código voluntário de conduta, adoção de atitudes pró-ativas, além do cumprimento das normas de Tecnologias Limpas/ Análise do Ciclo de Vida e integração total da responsabilidade empresarial em sua estrutura.

Assim, é possível analisar que o entendimento sobre o sistema de geração de resíduos, foi evoluindo e as empresas passaram a não somente resolver um problema já existente, mas a prevenir e evitá-los dentro deste contexto. O problema do resíduo, anteriormente visto como algo negativo, demostra hoje seu lado positivo vislumbrando uma oportunidade de melhoria de uma empresa, uma vez que o resíduo deixou de ser um resultado inerente e passou a ser o resultado de falta de eficiência no processo.

A técnica tradicional e que era mais utilizada nas décadas de 70 e 80: fim-de-tubo é uma solução paliativa, onde gera uma reação para remediar o problema que surgiu, mas sem o interesse de como foi gerado o problema, sem busca por mudanças, o que leva a conclusão de ser um processo ineficiente e sem evolução.

Com a produção mais limpa, técnica usada a partir década de 90, gera-se uma ação, com estudo de todo o processo para definir a causa dos problemas, refletindo na prevenção da geração de resíduos, efluentes e outros tipos de emissões, onde a proteção ambiental está como parte integrante de todos os processos da empresa e do desenvolvimento do produto, utilizando os recursos com uso eficiente, valorizando o investimento, os custos das empresas e o meio ambiente, evitando desperdícios.

E, segundo a Agência Brasileira de Desenvolvimento Industrial - ABIDI (2010), no Estudo Prospectivo Setorial Têxtil e de Confecção, a perspectiva para o cenário daqui a 15 anos, aponta que no âmbito socioambiental há uma grande preocupação com esta responsabilidade, e que reflete no aumento do consumo consciente. As empresas e os consumidores darão importância maior em relação ao uso correto e responsável de água e energia. Os consumidores e produtores terão valores naturalmente incorporados sobre reciclagem, reutilização e disposição de materiais e produtos. 
O quadro 4 demonstra estas tendências de comportamento e de consumo em relação à consciência e responsabilidade socioambiental, no qual há um visível aumento da incorporação da sustentabilidade nas ações das empresas e na exigência dos consumidores.

\begin{tabular}{|l|l|}
\hline \multicolumn{2}{|c|}{ Responsabilidade Socioambiental } \\
\hline 1 & $\begin{array}{l}\text { Efetiva preocupação com o meio ambiente e responsabilidade social, } \\
\text { com a valorização das empresas que as praticam }\end{array}$ \\
\hline 2 & Parcela de roupas recicláveis supera as não recicláveis \\
\hline 3 & $\begin{array}{l}\text { O consumidor compra roupas que não aumentam a sua conta de luz, } \\
\text { água, lixo e descarte }\end{array}$ \\
\hline 4 & $\begin{array}{l}\text { Continuam os estudos referentes à descoberta de novas fontes de } \\
\text { energia }\end{array}$ \\
\hline
\end{tabular}

Quadro 4 - Frases sobre Responsabilidade Socioambiental para 2023

Fonte: Abidi (2010)

Dados deste Estudo Prospectivo para 2023 conforme aponta a (ABIDI, 2010) também prevê tendências de Meio Ambiente para o Vestuário, tais como:

- Equipamentos que reduzem o consumo de água e energia;

- Processos que reduzem o consumo de água e energia, produção de efluentes e emissões de ruídos nocivos;

- Matérias-primas sintéticas recicláveis, fibras naturais orgânicas, fibras naturalmente coloridas: que proporcionam a diminuição de carga orgânica no tratamento;

- Maior eficiência em produtos auxiliares e insumos, sendo desenvolvidos em conjunto com fabricantes de equipamentos, buscando a redução de carga orgânica e melhoria do controle ambiental.

Estas tendências serão reforçadas pelo aumento de consumidores que se preocupam com os produtos que adquirem e consomem, sua procedência, sua responsabilidade sócio-ambiental. Haverá a interligação de designers, fabricantes de maquinários e produtores de insumos para um maior controle e desenvolvimento de equilíbrio de sustentabilidade, segurança e respeito ao ser - humano.

A aplicação da metodologia de produção mais limpa já é empregada em algumas empresas, e as de pequeno e médio porte podem adicionar medidas específicas para implementar a Produção Mais Limpa em seus processos, visto que é um processo importante para o desenvolvimento sustentável e para o melhor rendimento das empresas do Setor, minimizando a geração de resíduos, rumo a ecologia industrial, por meio de melhorias sustentáveis.

\section{Produção mais Limpa}

Este termo refere-se a aplicação contínua de uma estratégia econômica, ambiental e tecnológica integrada aos processos e produtos com o objetivo de aumentar a eficiência no uso de matérias-primas, água e energia através da não-geração, minimização ou reciclagem de resíduos gerados em um processo produtivo. A produção mais limpa está relacionada a todos os processos das empresas: da escolha da matéria prima, sua procedência, o processo de produção do produto, o design, o deslocamento e a logística da empresa, o pós-venda, e todas as etapas e escolhas da empresa que geram algum tipo de 
impacto ambiental. Isto irá gerar melhor rendimento de todos os setores, economia e lucro para empresa, menos desperdício e contribuição ao meio ambiente.

No Brasil, um projeto piloto de prevenção a poluição nas indústrias têxteis, que foi desenvolvido pelas empresas Cermatex e Santista (Serenza, 2002 apud Barreto, 2002), conseguiu bons resultados, influenciando a expansão do projeto para o setor. As empresas obtiveram participação e orientação da Companhia de Tecnologia de Saneamento Ambiental (CETESB), e entre as medidas escolhidas pelas empresas estão:

- Instalação de válvulas de bloqueio e torneiras com fechamento automático e a reutilização de água na área de tinturaria e acabamento dos tecidos, que resultou na redução de consumo de água de 111,22 mil m3/mês em 1997 para 83,73 mil m3/mês no ano de 2000 (SERENZA, 2002), apud (BARRETO, 2002). Na produção o consumo de água era de $33,89 \mathrm{l} / \mathrm{kg}$ de tecido e diminuiu no mesmo período para $27,68 \mathrm{l} / \mathrm{kg}$.

- Troca de lâmpadas fluorescentes pelas lâmpadas de vapor metálico e adesão de "timer" para acionar a iluminação, o que gerou uma economia de 473.500 $\mathrm{kW} / \mathrm{ano}$ no consumo de energia elétrica.

- Coleta e venda de soda cáustica utilizada no processo industrial, na estação de efluentes líquidos, o que gerou a diminuição do consumo de ácido sulfúrico em até $95 \%$.

Alguns cases de sucesso da indústria têxtil brasileira também pode servir como um indicativo e base para aplicação de um programa de Produção Mais Limpa na indústria de confecção com suas devidas adaptações e ajustes, e mesmo dentro de empresas do mesmo setor é preciso adotar medidas específicas para cada empresa, atendendo as suas particularidades, irregularidades ou problemas internos.

Avaliação de processos na confecção e mapeamento dos principais processos com geração de resíduos

Com base na análise da estrutura de empresas de confecção, com foco nas pequenas e médias empresas, foram detectados diversos processos, conforme apresentado na Figura 1.

É importante salientar que algumas das etapas apresentadas no quadro acima podem ser eliminadas ou trocadas de ordem de acordo com cada processo de desenvolvimento em cada empresa, podendo também haver etapas adicionais às aqui apresentadas. 


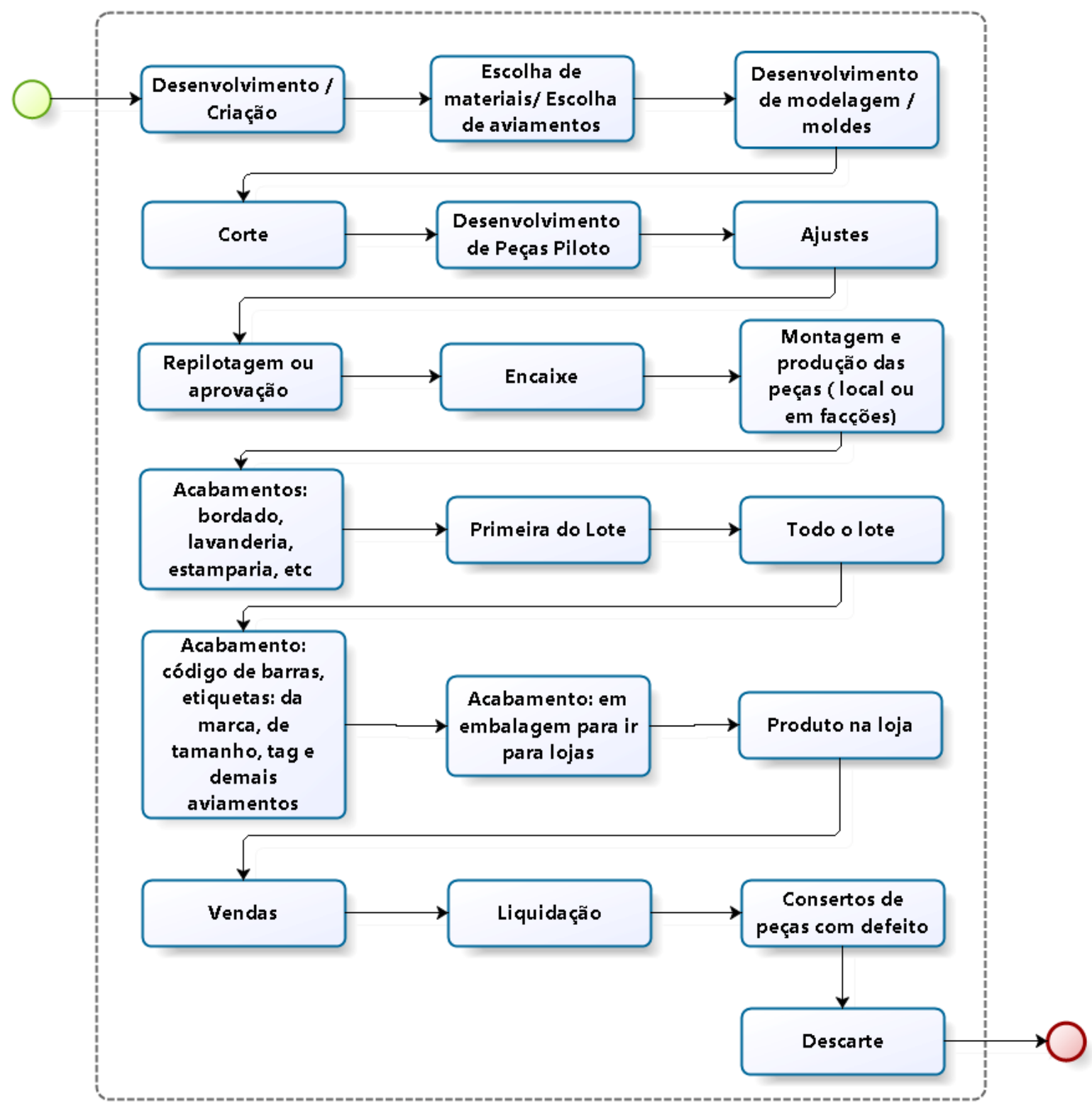

Figura 1 - Fluxograma dos Principais Processos de Confecção

Com o levantamento das etapas e processos principais da indústria de confecção é possível mapear as atividades que mais geram resíduos em empresas de confecção, isto também é possível com o conhecimento de inputs e outputs da empresa. Todas as etapas geram impactos ambientais, mas em geral algumas acarretam um impacto ainda maior como: a escolha de materiais, onde se define a qualidade da matéria-prima e de aviamentos, o rendimento do tecido e qualidade do material; a modelagem quando inadequada e sem os critérios ergonômicos requisitados; o corte sem um bom encaixe das peças que influirá em um mal aproveitamento do tecido e desperdício de material. 
Mapeamento de principais etapas de geração de resíduos em empresas de confecçães

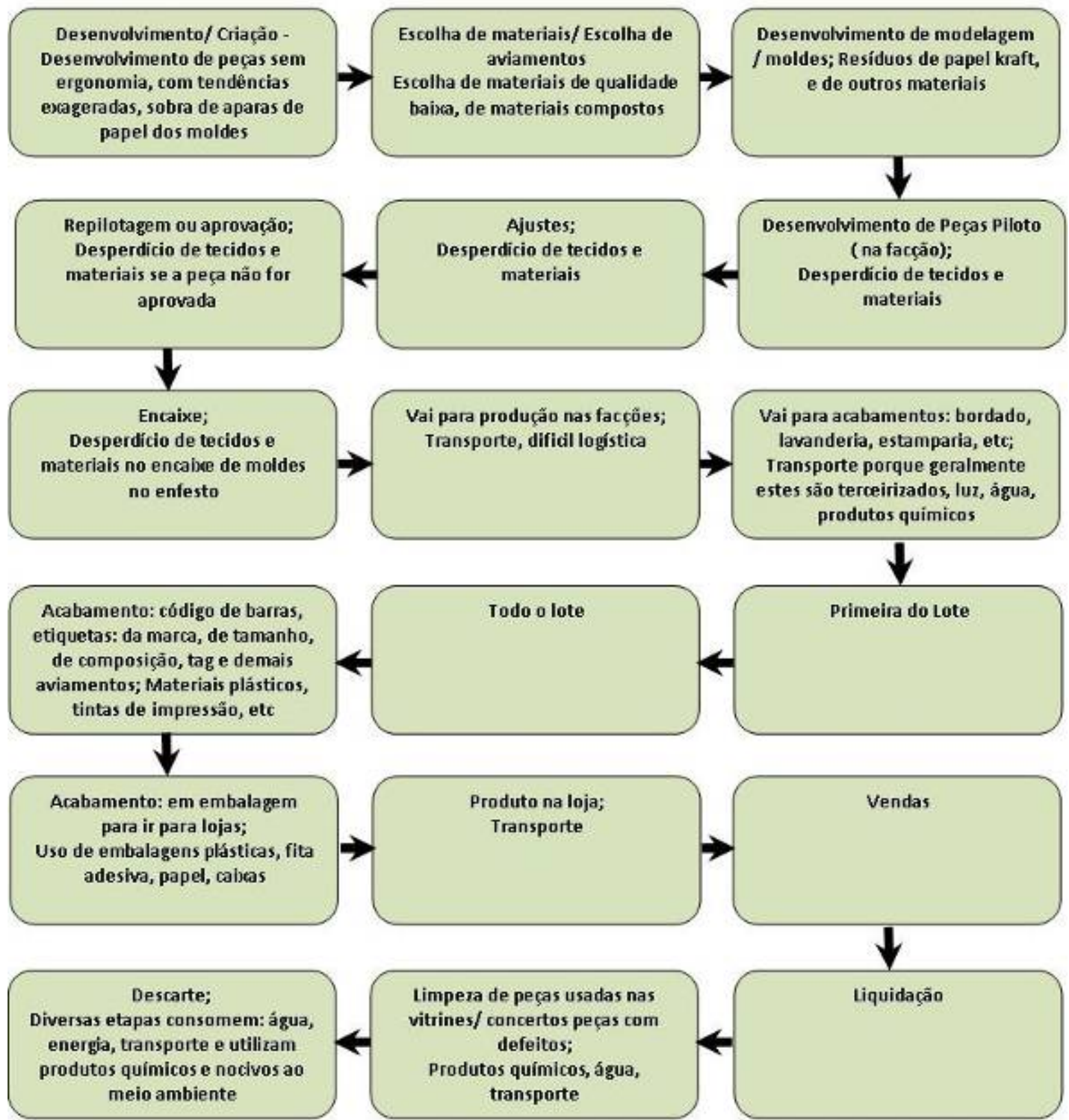

Figura 2 - Fluxograma do Mapeamento de principais etapas de geração de resíduos em confecções a partir da análise in loco em confecções

\section{Mapeamento de Inputs e Outputs do Processo}

Uma vez de posse ao conhecimento das etapas e do ciclo produtivo de uma indústria de pequeno e médio porte de confecção, devem ser analisados todos os inputs e outputs do processo, para avaliar o que causa impacto e geração de resíduos, e as etapas e itens que podem também ser evitados. Segundo o fluxograma de sistema operacional de confecção do Centro Nacional de Tecnologias Limpas, (2007) ENTRADAS significam os inputs e a SAÍDA os outputs do processo. Assim, é possível averiguar diversos outputs, que são os resíduos. Entre estes resíduos encontramos papel, sobras de tecidos, embalagens e 
aviamentos. Isso poderia ser evitado se fosse aplicada a Metodologia de Produção Mais Limpa.

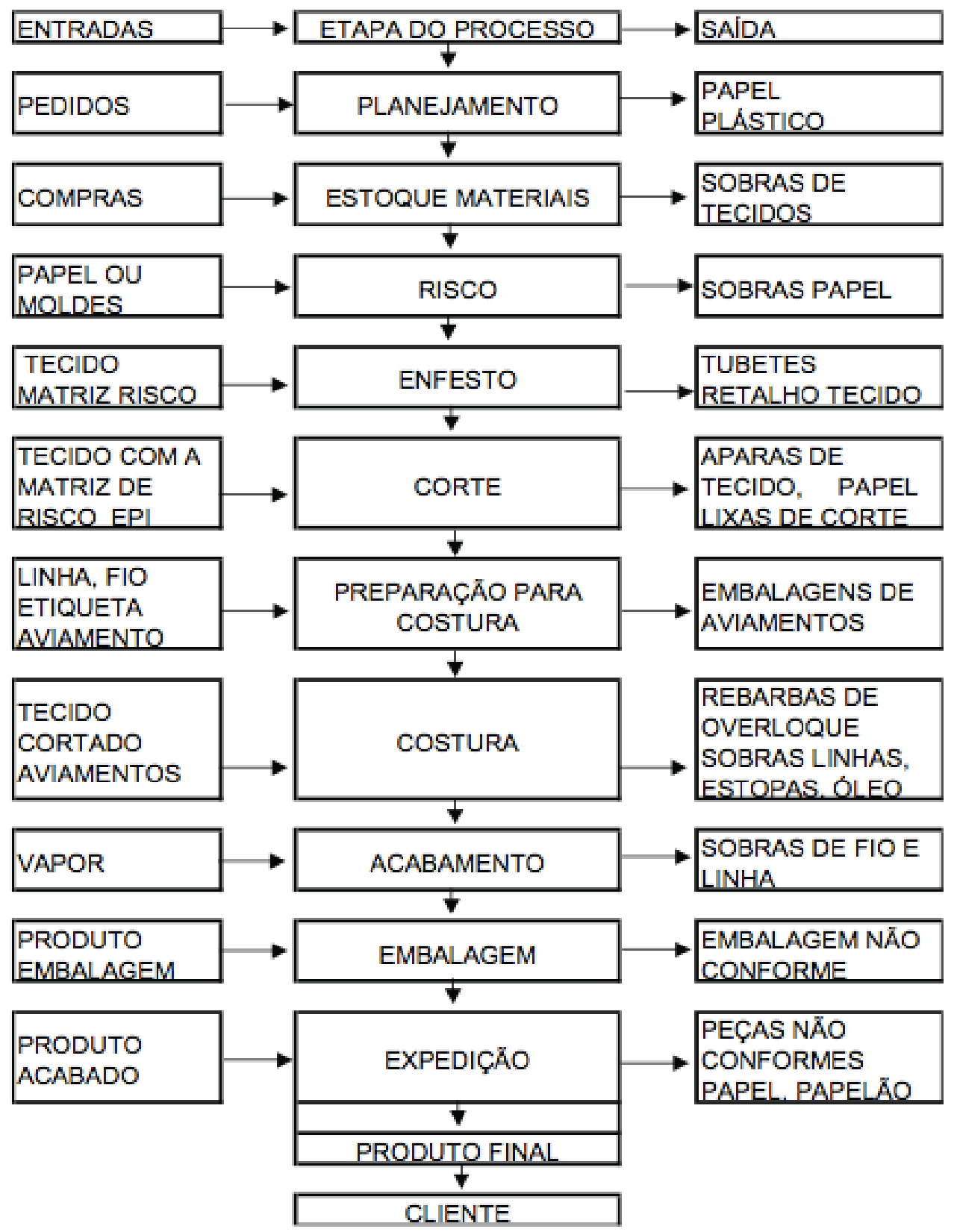

Figura 3 - Fluxograma de Entradas e saídas do sistema operacional de uma confecção Fonte: Centro Nacional de Tecnologias Limpas SENAI - CNTL (2007 p, 32)

Materiais e Métodos

Partiu-se da análise comparativa de uma empresa de confecção e por fluxogramas de produção mais limpa e de qualidade desenvolvidos pelo CNTL (2007), Neto e Gusmão (2008) e por Chambino e Correa (2010), com objetivo de detectar as melhores aplicações destes métodos para as indústrias de confecção e pequeno e médio porte. 
Para tal, avaliaram-se todos os detalhes dos fluxogramas dos autores acima que compreendem metodologias de qualidade aplicada as indústrias têxteis e metodologia de procedimentos para serem adotados na Indústria têxtil e de confecção para evitar a geração de resíduos. Tais parâmetros de análise nortearam o desenvolvimento dessa proposta de metodologia de produção mais limpa aplicada para indústrias de confecção de pequeno e médio porte.

Análise de fluxogramas de trabalho com produção mais limpa

Segundo o CNTL (2007) cada empresa deve entrar em um processo continuo de reformulação, buscando oportunidades e espaços para inserir a metodologia PmaisL (Produção mais Limpa), que age de forma preventiva, onde estuda-se a empresa em geral, suas etapas e seus problemas com a geração de resíduos. No fluxograma (Figura 4) podemos observar os níveis de oportunidade de PmaisL, que partem do princípio da redução de resíduos e emissões desde a fonte.

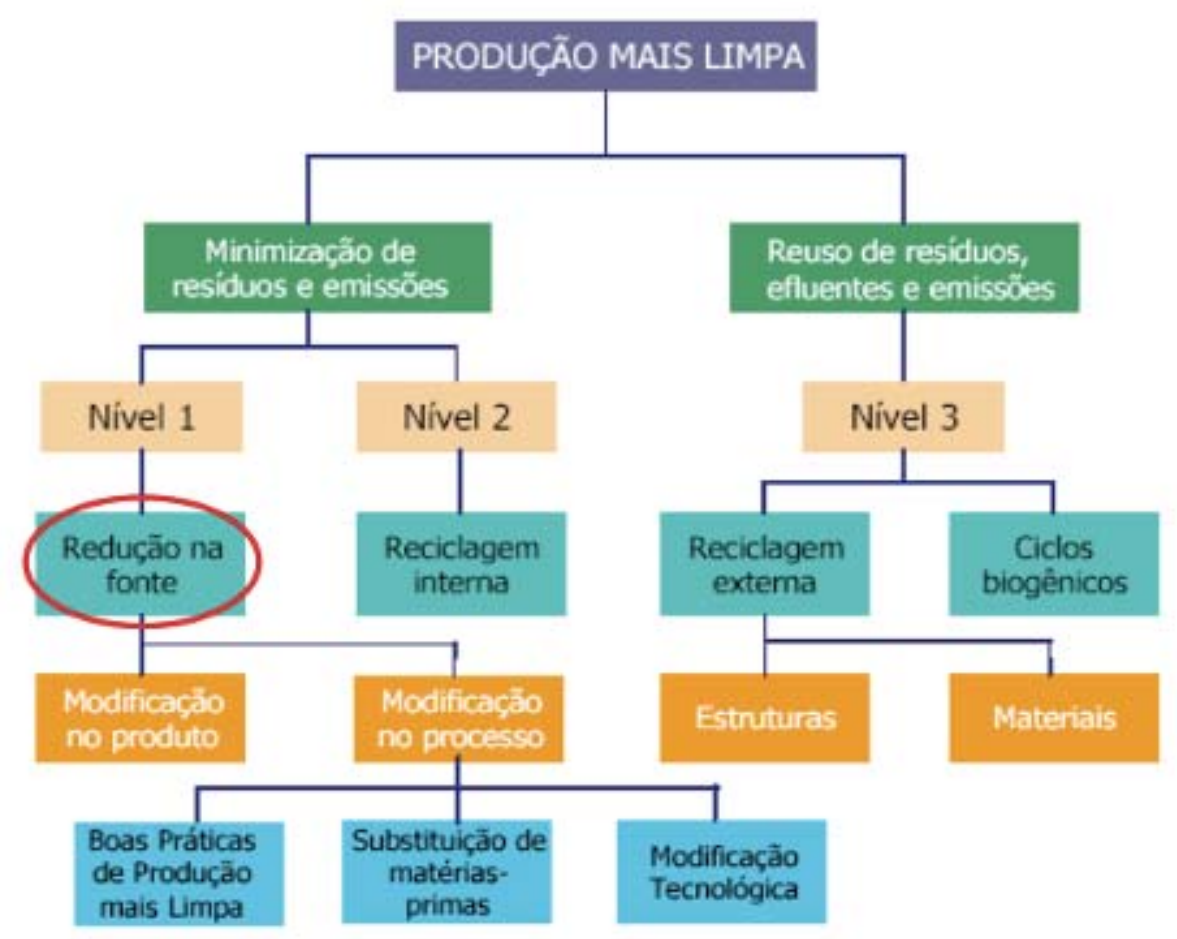

Figura 4 - Fluxograma de Aplicação de PmaisL Fonte: CNTL (2007, p. 15)

Processos de produção mais limpa nas indústrias

Segundo Neto e Gusmão (2008, p.3-5) uma metodologia com foco na qualidade para ser aplicada na cadeia têxtil e de confecção deve ser feita em 3 partes, sendo elas: 


\section{Metodologia com foco em qualidade para aplicar em empresas têxteis}

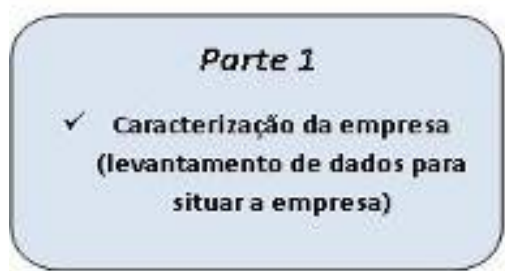

$\checkmark$ Como ê o planejamento produto?

$\checkmark$ Quais os processos utilizados?

$\checkmark$ Há quanto tempo utiliza este tipo de tecnologia? Há previsão de troca?

$\checkmark$ Como ocorre a integragăo produto/processo?

$\checkmark$ Qual a relaça com fornecedores de matériaprima?

$\checkmark$ Como é feito o Planejamento e Controle de produçือ?

$\checkmark$ Como é feita a gestão de materiais?

$\checkmark$ Como ê feito o treinamento das equipes de trabalho?

$\checkmark$ Há outras informaçăes relevantes?
Parte 3 - Planejamento de Qualidade

$\checkmark$ Qual a política de qualidade na empresa?

$\checkmark$ A política de qualidade da empresa é definida formal $e$ estritamente?

$\checkmark$ Os funcionários såo informados da política de qualidade da empresa?

$\checkmark$ como ê feita a inspeçăo da matéria-prima?

$\checkmark$ Como se consegue melhoria contínua dos processos? Que métodos e ferramentas săo utilizados para isto?

$\checkmark$ como se garante a manutençâo dos padróes espedficados para a produçå?

$\checkmark$ Săo utilizados gráficos de controle estatistico de qualidade dos processos?

$\checkmark$ como é feita a busca de inovaçôes para o processo produtivo?

$\checkmark$ Existem normas adotadas pela empresa para garantir a qualidade dos processos $\mathrm{e}$ produtos?

$\checkmark$ Existe controle de qualidade dos produtos?

$\checkmark$ Quais săo os principais itens de verificaçâo da qualidade dos processos?

$\checkmark$ Quais os principais resultados abtidos quanto à qualidade e produtividade?

$\checkmark$ A empresa enfrenta algum tipo de problema com os fornecedores de matériaprima/ equipamentos?

$\checkmark$ Quais sâo os critérios para a escolha dos fornecedores?

$\checkmark$ Há outras informaçođes relevantes?

Figura 5 - Fluxograma da Metodologia de checklist com foco na qualidade para empresas têxteis Fonte: Neto e Gusmão (2008)

Segundo Chambino e Correia (2010) a prevenção de resíduos é um passo fundamental na estratégia global de gestão de resíduos. A diminuição de resíduos se dará com a implementação de medidas de prevenção, sendo que uma menor quantidade de 
resíduos deverá ser reciclada, reutilizada ou irá para um destino final. Alguns dos procedimentos que podem ser aplicados para evitar a geração de resíduos:

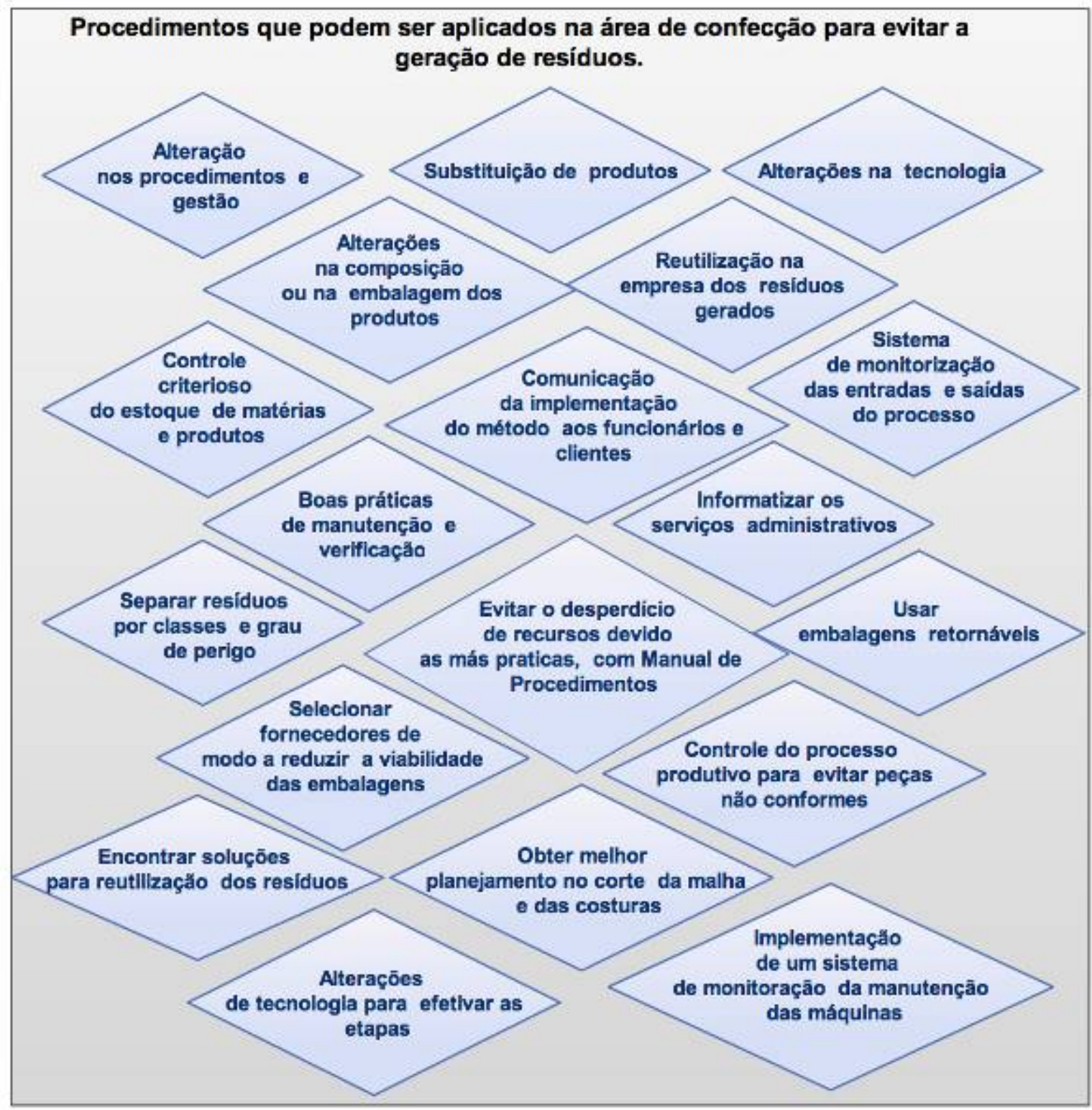

Quadro 5- Procedimentos para evitar geração de resíduos na área a de confecção Fonte: Chambino e Correa (2010)

\section{Proposta de metodologia de produção limpa para o setor de confecção}

Por meio da análise dos principais problemas encontrados nas indústrias de pequeno e médio porte de confeç̧ão e em especifico em um case de uma indústria de pequeno porte de Curitiba, detectou-se os aspectos aplicáveis para uma nova proposta metodológica segundo os parâmetros anteriormente descritos e que fundamentaram o desenvolvimento da Metodologia de Prevenção de Resíduos e Otimização de Produção Aplicada à Indústria de Confecção de Pequeno e Médio Porte, visando melhoria e eficiência em seus processos produtivos. 


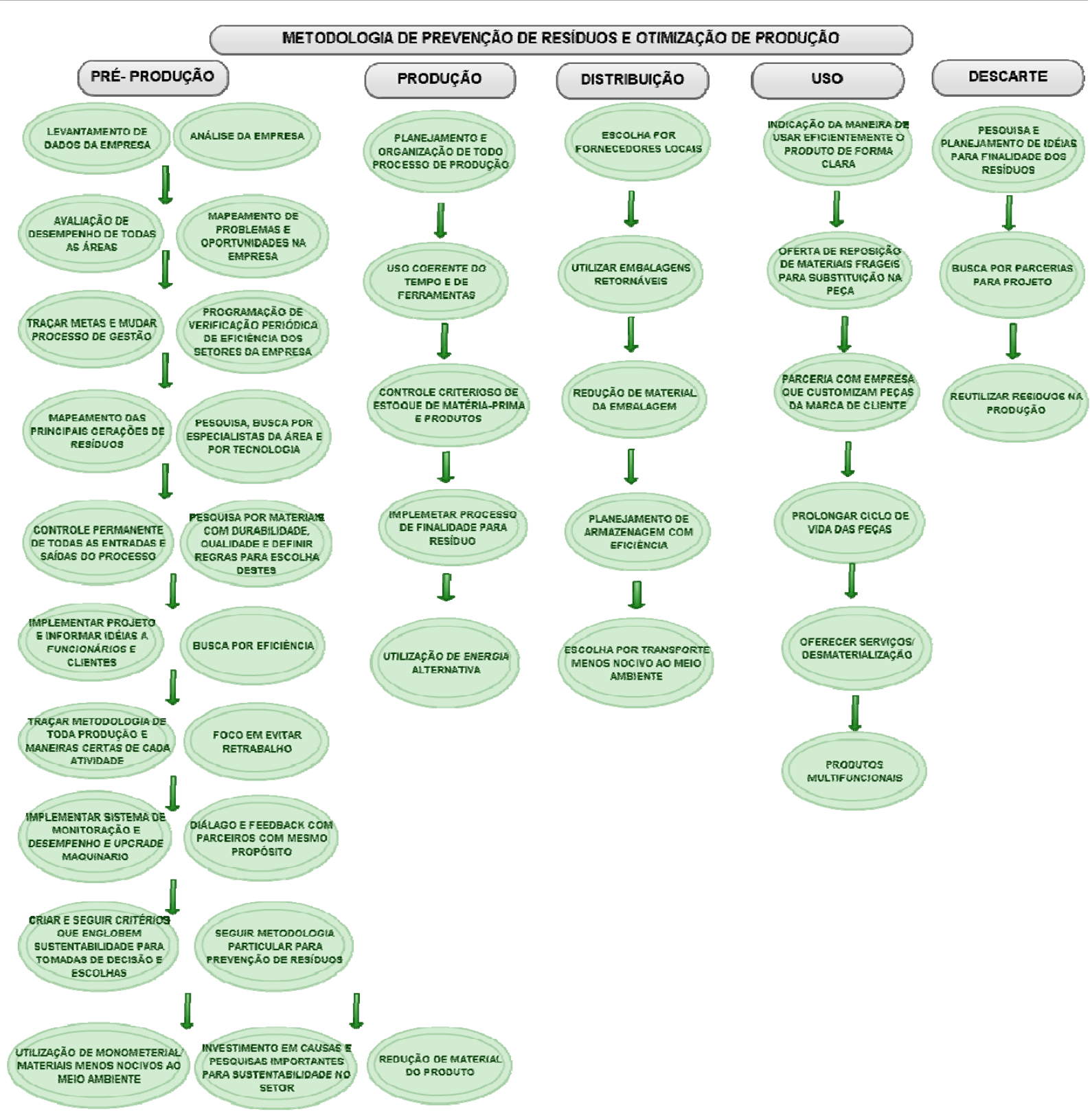

Figura 6 - Fluxograma da Metodologia de prevenção de resíduos e otimização de produção aplicada e indústria de confecção de pequeno e médio porte.

Partiu-se da avaliação dos problemas encontrados no case desta empresa e da análise dos métodos abordados, sendo eles: a falta de autoconhecimento da empresa, o uso de materiais sem pré-requisitos, a descentralização das atividades e de seu controle, resistência a mudanças e replanejamento de processos, processos de re-trabalho e falta de planejamento para implementar pré-requisitos gerais com foco na prevenção dos resíduos.

Também houve avaliação do mapeamento de cada etapa de seus processos produtivos, seus gargalos, seus inputs e outputs, da identificação da origem de geração de resíduos, da análise comparativa das metodologias citadas com focos similares, que gerou apontamentos de melhorias para tais metodologias na presente proposta a seguir apresentada.

A metodologia desenvolvida indica diversos passos adaptáveis entre si para aplicabilidade nas empresas em cinco etapas: de pré-produção, produção, distribuição, uso e 
descarte, ou seja, em todo o ciclo de vida do produto; o que norteia todos os processos pelo qual passa o produto, onde há maior probabilidade de encontrar os gargalos e os principais problemas de resíduos.

Com o levantamento de dados da empresa e seu autoconhecimento, é possível desenvolver a metodologia de forma coesa e encontrar soluções preventivas, pelo histórico de deficiência em processos da própria empresa ou baseada em cases de empresas similares que encontrar.

A metodologia ainda insere idéias para serem aplicadas na empresa e na concepção do produto para maior entendimento da aplicabilidade de critérios nos processos, e características importantes dos produtos que podem prolongar seu ciclo de vida. Apesar do escopo do trabalho ser a proposta de produção mais limpa, foram também pesquisadas algumas ações em Sistemas Produto-Serviço - PSS, visto que uma ação pode agregar a outra e ambas se complementarem.

\section{Considerações Finais}

Esta metodologia pode ser aplicada em empresas de confecção que estão começando no mercado ou as que desejam reformular seus processos, e que busquem por melhorias e diminuição da geração de resíduos. Possui vantagens por ser uma base adaptável para diversas empresas de pequeno e médio porte de confecção e que pode servir de referencia para outras empresas, de outros ramos e de outro porte, para uma produção mais limpa e com otimização na produção.

A aplicação e acompanhamento contínuo de uma metodologia de produção mais limpa nas indústrias proporcionam inúmeros benefícios para as empresas, seus consumidores e para o meio ambiente. Este método propõe a reformulação das estratégias e processos da empresa, com prevenção de seus resíduos e desperdícios, gerando lucros, melhor eficiência dos processos, e ainda cooperando com o meio ambiente.

\section{Referências}

ABIT. Gráfico de geração de emprego na indústria têxtil. Disponível em: http://www.abit.org.br/dados/postos.shtml> Acesso em: 4 out. 2010.

CHAMBINO, Tereza, CORREIA, Anabela. Prevenção de resíduos na indústria têxtil. Covilhã: Fitecom, 2007. Disponível em: <http://preresi.ineti.pt/> Acesso em: 20 nov. 2010.

CENTRO NACIONAL DE TECNOLOGIAS LIMPAS (CNTL). Produção mais limpa em confeç̧ões. Porto Alegre, 2007

KAZAZIAN, Thierry. Haverá a idade das coisas leves. São Paulo: Ed. Senac, 2005.

LIPOVETSKY, Gilles. O império do efêmero: a moda e seu destino nas sociedades modernas. São Paulo: Companhia das Letras, 2009.

MANZINI, Ezio, VEZZOLI, Carlo. O desenvolvimento de produtos sustentáveis. São Paulo: Edusp, 2002 
NETO, Pedro, GUSMÃO, Nilzeth. Uma visão de qualidade na cadeia têxtil em empresas de pequeno e médio porte. CONGRESSO NACIONAL DE EXCELÊNCIA EM GESTÃO, 4., 2008, São Paulo. Anais... São Paulo:UNIP- Universidade Paulista, 2008.

POPCORN, Faith. Click: 16 tendências que Irão transformar sua vida, seu trabalho e seus negócios no futuro. Rio de Janeiro: Campus, 1997.

SEBRAE. Dados das empresas. Disponível em: <http://www.sebrae.com.br/momento/queroabrir-um-negocio/integra_bia?ident_unico=97> Acesso em: 23 nov. 2010.

SERENZA, Eli. Projeto de redução de consumo e geração de resíduos. Disponível em: http://www.ambiente.sp.gov.br/destaque/industria_textil1.htm Acesso em: 30 out. 2010. 